\title{
Experimental Research on Bearing Characteristics of the Asphalt Pavement Containing Buried Pipeline
}

\author{
Hailiang Xu (D), Jining Qin (D), Hehuan Ren (D), Jindou Sun (D), and Lian He $(\mathbb{D}$ \\ Department of Civil Engineering, North China University of Technology, Beijing, China \\ Correspondence should be addressed to Jining Qin; qin_1221@qq.com
}

Received 3 December 2020; Revised 20 February 2021; Accepted 6 March 2021; Published 22 March 2021

Academic Editor: William Guo

Copyright (C) 2021 Hailiang Xu et al. This is an open access article distributed under the Creative Commons Attribution License, which permits unrestricted use, distribution, and reproduction in any medium, provided the original work is properly cited.

\begin{abstract}
The bearing characteristics of the asphalt pavement structure are greatly influenced by buried pipelines. Improper treatment of buried pipelines would cause early damage to pavement structure. By the digital speckle correlation method (DSCM), the experimental research on bearing characteristics of the asphalt pavement containing buried pipe was carried out. The mechanical characteristics of the asphalt pavement structure are studied under four different pipeline burial conditions. The vertical displacement and strain values of each layer of the asphalt pavement structure are obtained under four operating conditions. The results showed that (1) the digital speckle observation test method can accurately obtain the displacement and strain values of each layer of asphalt pavement structure containing buried pipeline, and the application effect is good. Compared with the traditional contact strain measurement method, this method is simple and accurate and can provide effective analysis data for experimental research. (2) There exists an interlayer effect of the asphalt pavement structure. The vertical displacement value and the strain value are discontinuities and can suddenly change between two adjacent layers. At the same time, the vertical strain and the shear strain concentration phenomenon appear at the bottom of each layer, especially at the bottom of the upper layer and the subbase layer of asphalt. (3) Affected by the buried pipelines, the vertical displacement value of the asphalt pavement structure reduces, and the tensile and shear strain values of asphalt pavement structure increase. The subbase layer of asphalt is most affected by the buried pipelines, which accelerated the destruction of the asphalt pavement structure.
\end{abstract}

\section{Introduction}

Urban road is not only the carrier of transportation but also the main channel of municipal pipelines. With the existence of buried pipelines under roads, the stress state of road pavement structure will inevitably be affected (especially by shallow pipelines) [1]. A large number of existing projects show that the improper installation and disposal of buried pipelines often lead to the failure of pavement structure to reach the design life. Take the 2013 field survey of road surface damage in Tiancun Mountain road in Beijing as an example. Ninety-four cracks were found in the vertical and horizontal directions within a range of three kilometers, among which 51 occurred at or near the location of buried municipal pipelines, accounting for about $55 \%$ of the total cracks. The cracks of the asphalt pavement structure at the buried pipeline are shown in Figure 1.
At present, there is no clear control index for the buried pipeline under pavement structure from the point of view of pavement structure. The adverse effects of buried pipelines on pavement structure are not considered in the design process of pavement structure. The existing research mainly focuses on the stress state of pipelines under vehicle load [1-4].

In the experimental study of pavement structure stress, due to the limitation of measuring and testing means, sensors such as the pressure box, asphalt strain gauge, and axis gauge are mainly used $[5,6]$. Although these testing methods can reflect the overall stress condition of pavement structure, there are still some unfavorable factors such as the limited number of locations, the inconvenience of testing the original parts, and the great influence of the embedded quality on the testing accuracy. In view of the above problems in the experimental study, this study uses a new 
digital speckle correlation method to study the bearing characteristics of asphalt pavement structure under the coupling action of driving load and buried pipeline.

\section{Basic Principle and Introduction of the Digital Speckle Correlation Method}

The digital speckle correlation method (DSCM) was proposed in the early 1980s by a Japanese scientist Yamaguchi [7] and Peter and American scientists Rnaosn et al. [8]. They proposed their experimental method, respectively, mainly using optical observation and postimage processing. The method is based on gray scale analysis of object surface speckle to obtain displacement and the strain information measurement method. Advantages of this method include global observation, adjustable range accuracy, noncontact mode, simple operation, and reliable data.

The principle of DSCM is that the predeformed image is called "reference image" and the postdeformed image is called "target image." After loading, the speckle gray information of the reference image and the target image will be slightly different, the essence of which is caused by displacement and strain. DSCM carries out a correlation search on the speckle pattern before and after deformation, analyzes the gray distribution difference of each area, and finally realizes the measurement of displacement and strain.

The measurement process of DSCM is simple. Compared with the contact strain measurement method, the equipment does not need to contact with the specimen during the measurement, which omits the installation of the sensor and eliminates the errors caused in the installation process. The contact measurement can only reflect the strain information of the sensor position, while DSCM can obtain the full-field information of the speckle field photographed under the lens and can measure the continuous change process of the speckle field according to the continuous shooting of the camera.

In graphics processing, gray scale is the carrier of graphics data (gray scale is the speckle field formed by white spots on a black background or white spots on a white background). DSCM establishes the correlation function between the predeformation image gray level and postdeformation image gray level and converts graphic data into digital data by using computational software.

The density and diameter of the gray scale directly affect the accuracy of software numerical calculation. In the gray image taken by camera, the gray search algorithm is also very important. The classical gray search methods include the fineness search method, cross-search method, climbing search method, neighborhood search method, and Newton Lafayette partial differential correction method. The new search method includes the FFT search method in frequency domain. The search method used in the experiment is the cross-search method. The cross-search method reduces the search time and improves the search efficiency because it simplifies the twodimensional search method to one-dimension.

The coordinate matching diagram of the calculation process of the digital speckle correlation method is shown in

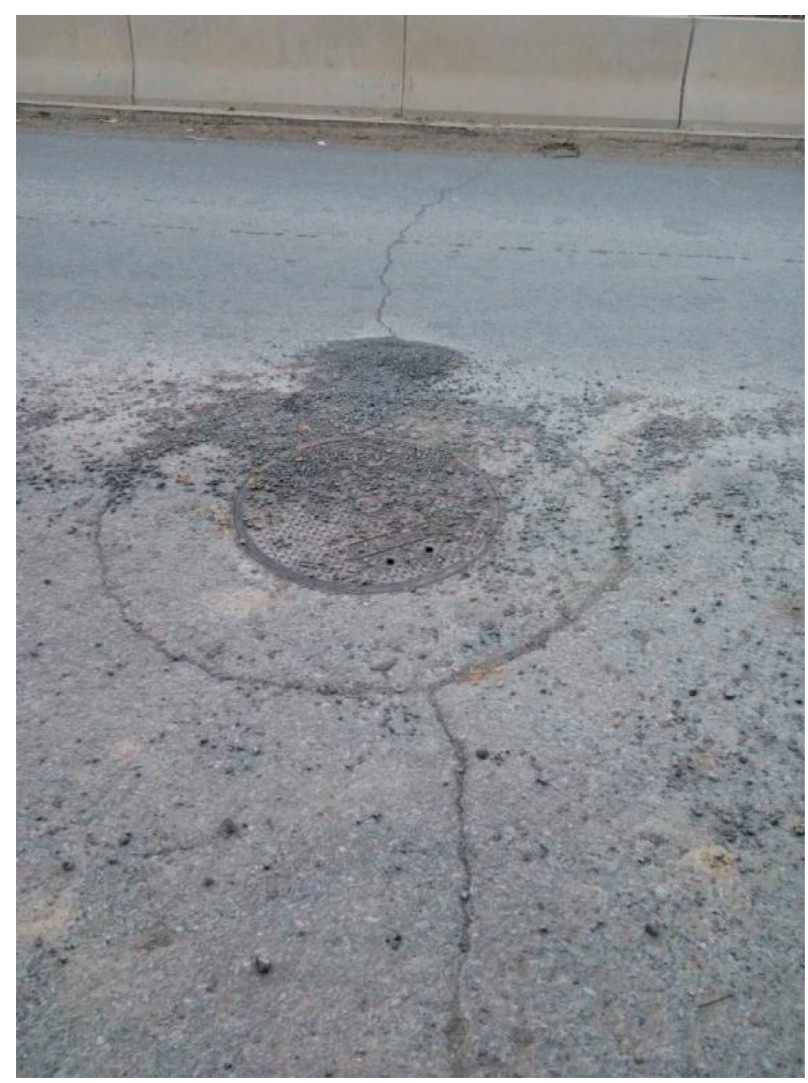

FIGURE 1: Crack of asphalt pavement structure.

Figure 2. The reference subarea centered on $P$ is calculated to realize the search. The region can be divided into $(2 n+1) \times(2 n+1)$ grids. By referring to the measurement point $P$ in the image, the point $P^{*}$ with the greatest similarity to $P$ can be found by searching the target subarea in the target image through the limited threshold value.

According to the continuity assumption of displacement field, the relationship between horizontal displacement and vertical displacement of any point $Q$ in the image subarea can be expressed by equations (1) and (2), and the strain field relationship can be expressed by equation (3) [9]. The displacement field of the whole speckle image can be obtained by calculating multiple image subareas, and then, the strain field can be calculated. $(\Delta x, \Delta y)$ is the distance between point $O$ and the center of the subarea. $L$ is the length before deformation, and $\Delta L$ is its variation after deformation.

$$
\begin{aligned}
& u=u_{0}+\frac{\partial u}{\partial y} \cdot \Delta x+\frac{\partial u}{\partial y} \Delta y, \\
& v=v_{0}+\frac{\partial v}{\partial x} \cdot \Delta x+\frac{\partial v}{\partial y} \cdot \Delta y, \\
& \varepsilon=\lim _{L \longrightarrow 0}\left(\frac{\Delta L}{L}\right) .
\end{aligned}
$$

The general standardized correlation function common to DSCM is given in the following equation [10-12]. 


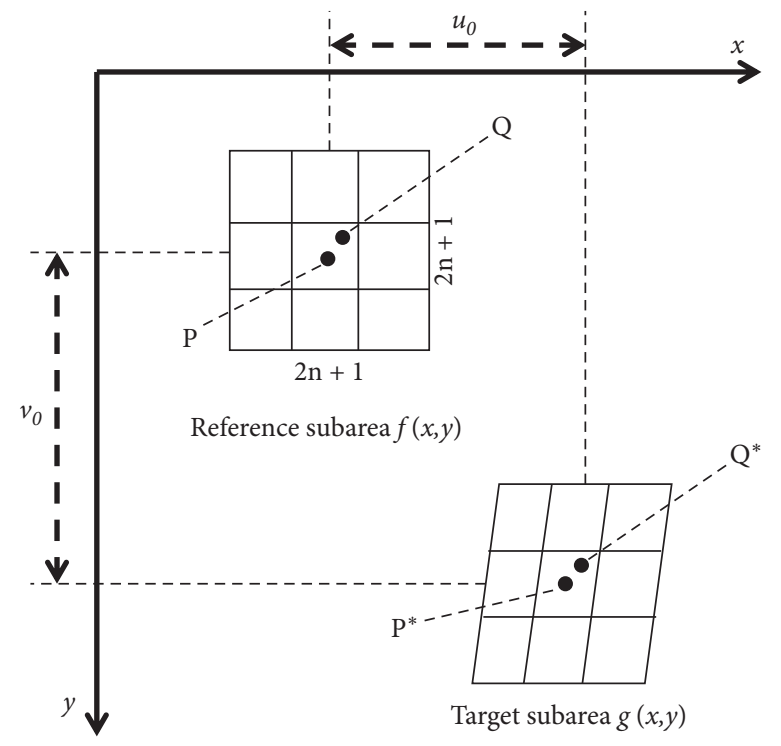

FIgURE 2: Coordinate matching diagram.

$$
C(u, v)=\frac{\sum_{x=-2 n+1}^{2 n+1} \sum_{y=-2 n+1}^{2 n+1}[f(x, y) g(x+u, y+v)]}{\sqrt{\sum_{x=-2 n+1}^{2 n+1} \sum_{y=-2 n+1}^{2 n+1} f^{2}(x, y)} \sqrt{\sum_{x=-2 n+1}^{2 n+1} \sum_{y=-2 n+1}^{2 n+1} g^{2}(x+u, y+v)}} .
$$

In the formula, $f(x, y)$ is the gray function of the reference image before deformation at a certain point $(x, y)$, $g(x+u, y+v)$ is the gray function of the target image after deformation at a point $(x+u, y+v)$, and the range of the correlation coefficient $C(u, v)$ is $[0,1]$. The larger the correlation coefficient is, the better the matching degree is.

In this study, the method of the digital speckle correlation is used to obtain the displacement and strain data of pavement structure directly through noncontact optical measurement. The changes of pavement structure can be observed and analyzed intuitively.

\section{Manufacture of Asphalt Road Structural Specimens Containing Buried Pipeline}

The preparation of structural specimens includes the asphalt layer (upper layer, middle layer, and lower layer), cementstabilized macadam layer (upper base layer and lower base layer), and pipelines. The settings of structural parameters are given in Table 1.

For the preparation of asphalt structural layer materials, commercial asphalt materials AC-13, AC-20, and AC-25 were poured into the asphalt mold, respectively, and compacted. The cement-stabilized macadam layer is prepared at a 5\% cement-stabilized macadam mixture ratio and is proportioned at the mass ratio of cement: coarse aggregate: fine aggregate: sand: water $=113: 906: 566: 793: 112$. The combination of each layer of the structure mainly considers the flatness and tightness of the contact surface. Equipped with cement, the cement mortar with sand of $1: 3$ is used to smooth and connect the top surface of water-stable base course; the connection of the asphalt structural layer is first wetted with waterborne asphalt permeable oil at the bottom layer and then evenly coated with oily 70 \# asphalt viscous oil, which combines the two layers before static pressing for 12 hours.

The PVC pipes are buried in the center of the road structure when the water-stabilized layer is poured. The center of the pipes is $0.22 \mathrm{~m}$ away from the surface of the specimens (shallow-buried pipes, where the upper edge of the pipes is at the bottom of the asphalt layer), $0.36 \mathrm{~m}$ (middle-buried pipes), $0.50 \mathrm{~m}$ (deep-buried pipes), and no pipes. The preparation of specimens meets the requirements of relevant specifications and mechanical indexes.

After the specimens are prepared, the artificial speckle field is sprayed on the observation surface, and the artificial speckle field is sprayed on the central area of the specimens at $20 \mathrm{~cm} \times 56 \mathrm{~cm}$. The black paint is used for priming. After the black paint is dried, white spots are evenly sprayed with white paint. Taking the middle-buried pipeline as an example, the structure of the specimen is shown in Figure 3.

The test system consists of WAW-600 electrohydraulic servo universal testing machine, CCD camera, and corresponding control acquisition system. Figures 4 and 5 represent the schematic diagram of the test system and the layout of the indoor model test, respectively. The experimental load is used in the "urban road design code" (CJJ 169-2012), a grounding pressure of $0.70 \mathrm{MPa}$.

\section{Analysis of the influence of buried pipeline on pavement structure}

Through the digital speckle correlation method, the influence of buried pipelines on the road structure is calculated 
TABLE 1: Structure-layer parameters.

\begin{tabular}{lcccc}
\hline Horizon & Material & Length $(\mathrm{m})$ & Width $(\mathrm{m})$ & Thickness $(\mathrm{m})$ \\
\hline Asphalt upper layer & AC-13 & 0.8 & 0.3 & 0.04 \\
Asphalt middle layer & AC-20 & 0.8 & 0.3 & 0.3 \\
Asphalt lower layer & AC-25 & 0.8 & 0.3 & 0.07 \\
Upper water-stabilization bases & Cement-stabilized macadam & 0.8 & 0.3 & 0.2 \\
Lower water-stabilization bases & Cement-stabilized macadam & 0.8 & External diameter, $110 \mathrm{~mm}$ \\
Pipeline & PVC & & Wall thickness, $10 \mathrm{~mm}$ \\
\hline
\end{tabular}

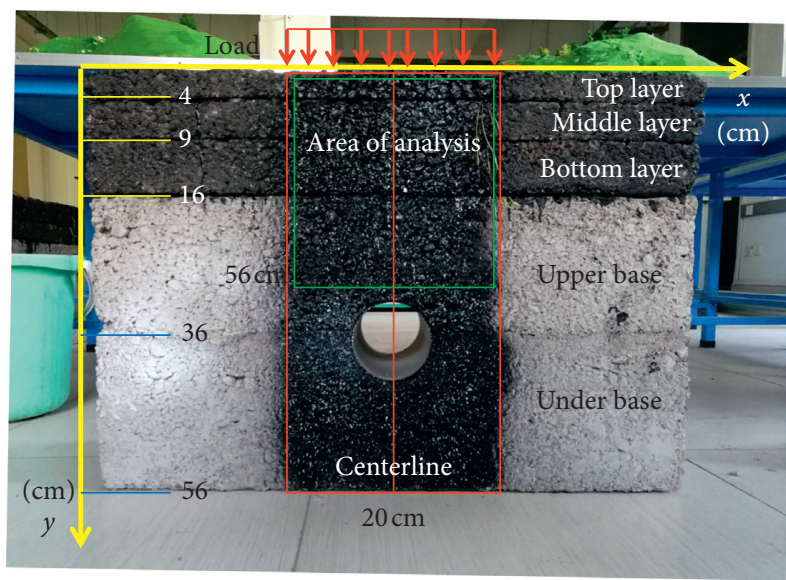

FIgURE 3: Middle-buried pipeline structure.

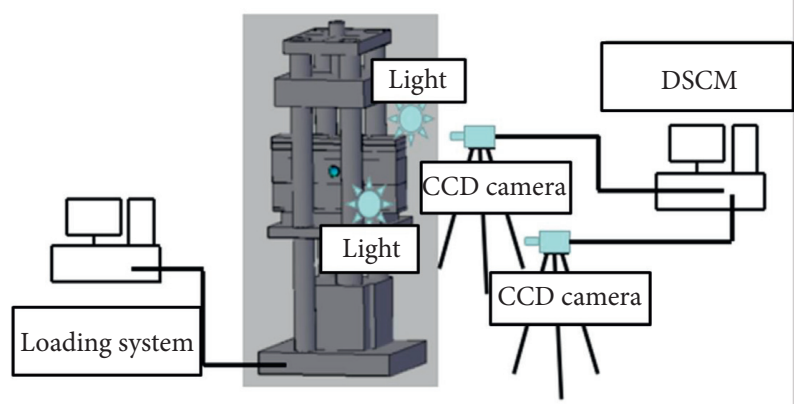

Figure 4: Schematic diagram of the experimental system.

under different buried pipelines. Aiming at the form of structural failure, the vertical displacement (deflection value), tension-compression strain, and shear strain of the road structural layer are selected as the main analysis indexes.

4.1. Analysis of the Effect of Buried Pipeline on the Vertical Displacement of the Structural Layer. The vertical displacement (deflection value) of road structure is an important reference value in road structure design. The vertical displacement nephogram of the structural analysis area under different buried depths of the pipeline obtained during the test is shown in Figures 6-9.

The pixel data of displacement cloud image are multiplied by a certain ratio (the ratio of the difference of pixel

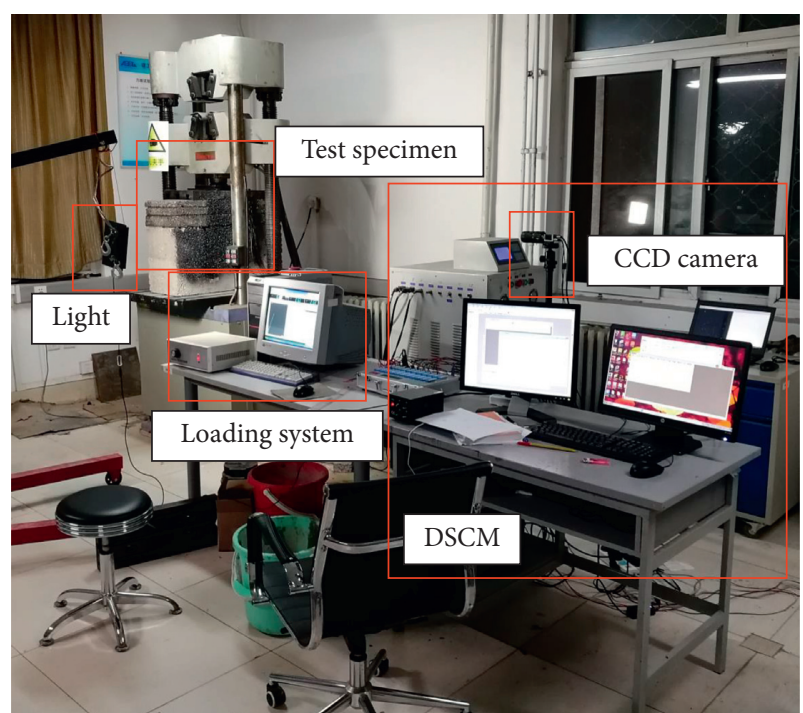

FiguRe 5: Laboratory model test.

points and the actual distance), before being converted it into the actual displacement unit millimeter. The vertical displacement values on the central line are selected for specific analysis, as shown in Figure 10.

From Figure 10, we can see that

(1) Pipeline embedment reduces the vertical displacement of each layer. With the decrease of pipeline embedment depth, the trend of reducing the displacement of each layer of pavement becomes more obvious. Taking the deflection value of the asphalt upper layer as an example, the deflection value is 26.09 (unit: less than $0.01 \mathrm{~mm}$ ) under the condition of no pipeline embedding and $10.65(0.01 \mathrm{~mm})$ under the condition of shallow pipeline embedding, with a decrease of $59.2 \%$. This is caused by the support of the pipe.

(2) As the road material is layered, the strength of each layer is different. In the road structure, the vertical displacement values are discontinuous, and the displacement values at the connections between layers of the structure have abrupt changes. This is shown in Table 2. This phenomenon is different from the continuity condition of displacement assumed in most current calculation models. Taking pipeline less asphalt as an example, the abrupt change values of the upper, middle, and lower surface layers of asphalt 


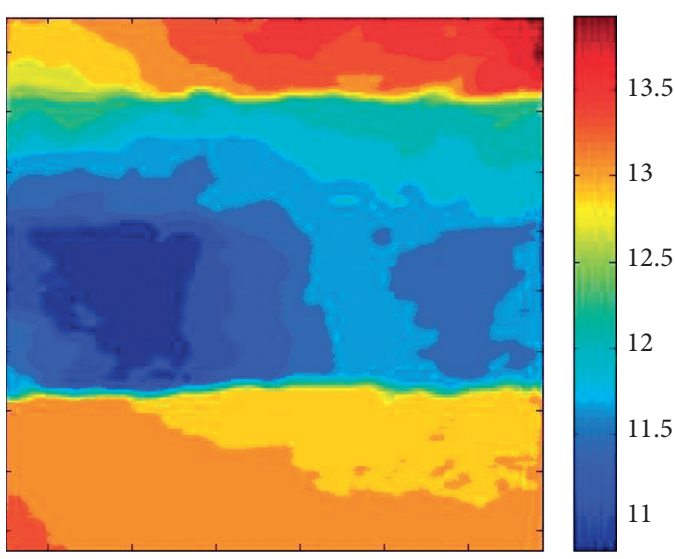

FIgURE 6: Vertical displacement of no buried pipe.

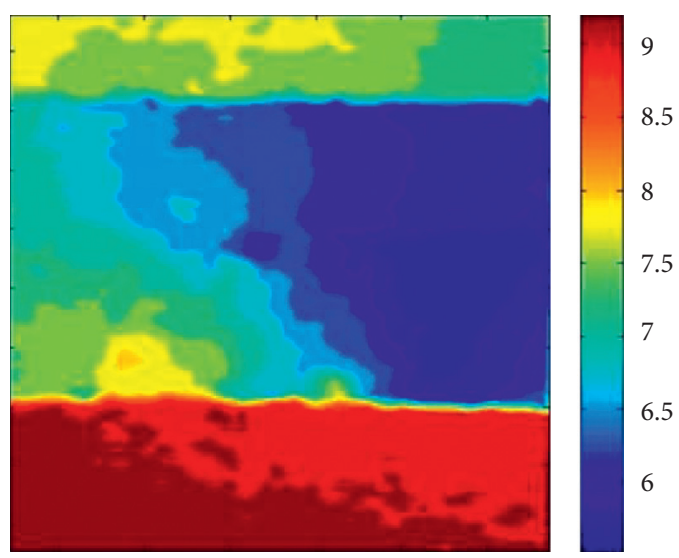

Figure 7: Vertical displacement of deep-buried pipe.

are 1.98 (unit: $0.01 \mathrm{~mm}$ ), 0.3 (unit: $0.01 \mathrm{~mm}$ ), and 2.95 (unit: $0.01 \mathrm{~mm}$ ), respectively. The abrupt change ranges are $7.58 \%, 0.13 \%$, and $12.74 \%$. The abrupt change between layers in other working conditions is shown in Table 3.

(3) Among the abrupt changes of interlayer displacement, the abrupt changes of the displacement of the upper layer and the bottom layer of the lower layer of asphalt are the most obvious. However, the two trends are opposite. The displacement between the upper layer of asphalt and the middle layer of asphalt decreases, while the displacement between the lower layer of asphalt and the water-stabilized macadam increases.

The buried pipeline supports the road and reduces the vertical displacement of each layer. The road material is layered, and the strength of each layer material is different, which makes the displacement value at the junction between layers abrupt. The abrupt displacement of the upper layer of asphalt and the bottom layer of asphalt is the most obvious.

\subsection{Analysis of the Influence of Buried Pipeline on Tension and} Compression Strain of Pavement Structure. The strain of tension and compression stress in each layer of pavement

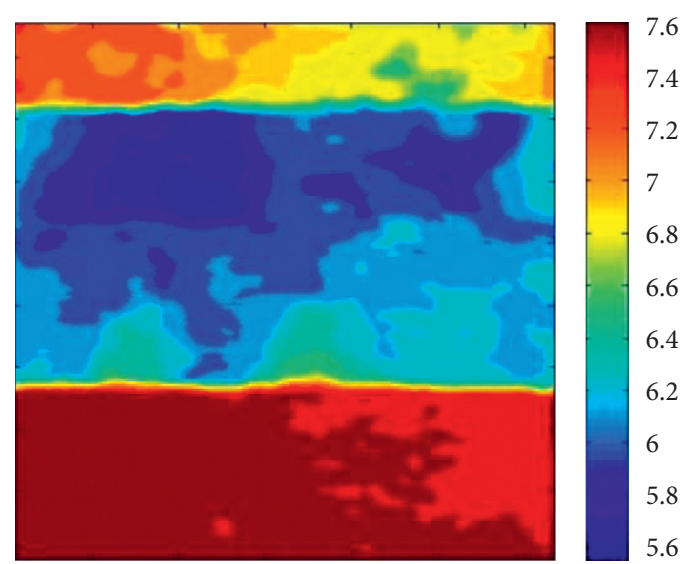

Figure 8: Vertical displacement of middle-buried pipe.

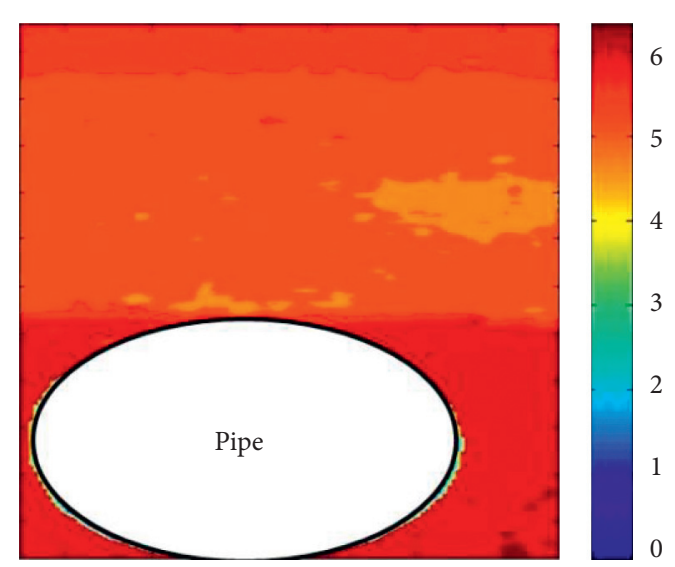

Figure 9: Vertical displacement of shallow-buried pipe.

structure is an important research content of pavement structure stress. During the test, the tension and compression strain nephogram of the pavement structure analysis area under different buried depths is shown in Figures 11-14

The vertical strain values observed in Figures 11-14 are sorted out, and the strains at different buried depths of pipelines at the center line are selected for analysis, as shown in Figure 15.

From Figures 11-14, it can be seen intuitively that the pavement structure is mainly compressed, but the bottom of the asphalt layer appears at tension state. At the same time, it is shown in Figure 15 that

(1) The phenomenon of strain concentration appears at the bottom of each layer of pavement structure, that is, the maximum strain of each layer appears at the bottom of this layer. Among them, the strain concentration of the upper layer and the lower layer of asphalt is the most obvious. The maximum vertical strain and variation amplitude of pipeline under different burial depths are shown in Table 3. It can be seen from Table 3 that the influence of pipeline depth on the stress state of pavement structure cannot be ignored. 


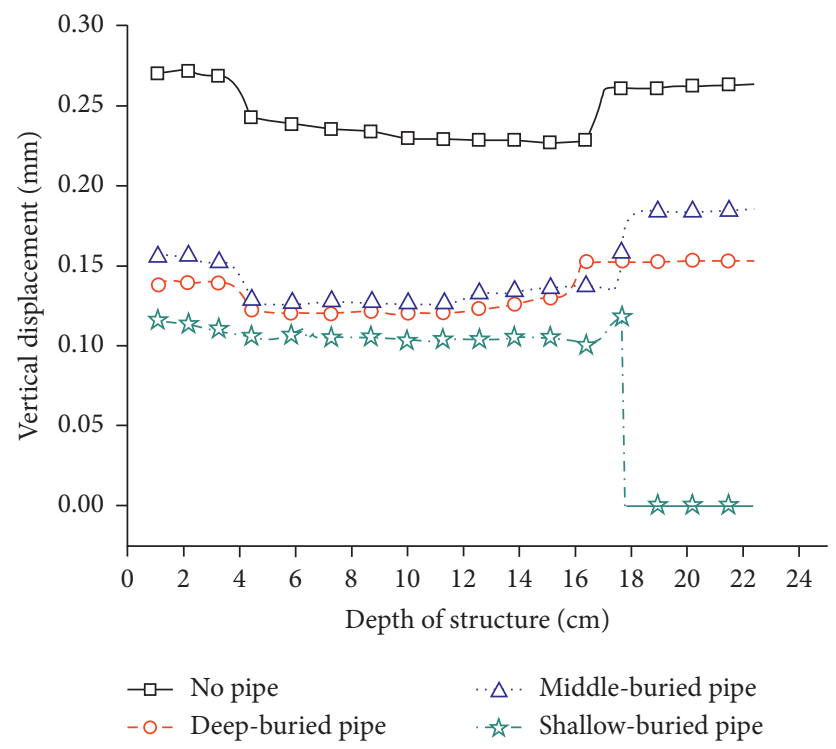

Figure 10: Vertical displacement curve of the center line.

TABLE 2: Vertical displacement of structure interlayer.

\begin{tabular}{|c|c|c|c|c|c|c|}
\hline \multirow{2}{*}{$\begin{array}{l}\text { Condition }(\mathrm{mm}) \\
\text { No pipeline }\end{array}$} & \multicolumn{2}{|c|}{$\begin{array}{c}\text { Bottom of the upper } \\
\text { layer/Top of the middle } \\
\text { layer }\end{array}$} & \multicolumn{2}{|c|}{$\begin{array}{l}\text { Bottom of the middle } \\
\text { layer/Top of the lower } \\
\text { layer }\end{array}$} & \multicolumn{2}{|c|}{$\begin{array}{c}\text { Bottom of the lower layer/ } \\
\text { Top of water-stabilization } \\
\text { bases }\end{array}$} \\
\hline & 0.2609 & 0.2411 & 0.2293 & 0.2290 & 0.2313 & 0.2608 \\
\hline Rangeability & \multicolumn{2}{|c|}{$-7.58 \%$} & \multicolumn{2}{|c|}{$-0.13 \%$} & \multicolumn{2}{|c|}{$12.74 \%$} \\
\hline Deep-buried pipe & 0.1928 & 0.1809 & 0.1818 & 0.1796 & 0.1938 & 0.2127 \\
\hline Rangeability & \multicolumn{2}{|c|}{$-6.14 \%$} & \multicolumn{2}{|c|}{$-1.16 \%$} & \multicolumn{2}{|c|}{$9.75 \%$} \\
\hline Middle-buried pipe & 0.1448 & 0.1253 & 0.1161 & 0.1053 & 0.1400 & 0.1833 \\
\hline Rangeability & \multicolumn{2}{|c|}{$-13.46 \%$} & \multicolumn{2}{|c|}{$-9.27 \%$} & \multicolumn{2}{|c|}{$30.91 \%$} \\
\hline Shallow-buried pipe & 0.1065 & 0.1059 & 0.1031 & 0.1022 & 0.1026 & 0.1179 \\
\hline Rangeability & \multicolumn{2}{|c|}{$-0.58 \%$} & \multicolumn{2}{|c|}{$-0.93 \%$} & \multicolumn{2}{|c|}{$14.87 \%$} \\
\hline
\end{tabular}

TABle 3: Maximum vertical strain of asphalt layer bottom.

\begin{tabular}{lccc}
\hline Condition & Bottom of the upper layer $(\varepsilon)$ & Bottom of the middle layer $(\varepsilon)$ & Bottom of the lower layer $(\varepsilon)$ \\
\hline No pipeline & -0.0251 & -0.0033 & 0.0304 \\
Deep-buried pipe & -0.0252 & 0.0013 & 0.0320 \\
Rangeability & $0.24 \%$ & $-138.18 \%$ & $5.40 \%$ \\
Middle-buried pipe & -0.0263 & -0.0013 & 0.0436 \\
Rangeability & $4.78 \%$ & $-61.21 \%$ & $43.69 \%$ \\
Shallow-buried pipe & -0.0156 & -0.0078 & 0.0544 \\
Rangeability & $-38.03 \%$ & $137.27 \%$ & $79.24 \%$ \\
\hline
\end{tabular}

(2) Under the condition of different buried depths of pipelines, the maximum compressive strain appears above the asphalt layer and the maximum tensile strain appears below the asphalt layer.

(3) The bottom tension strain of the asphalt layer is most obviously affected by the buried depth of the pipelines. With the decrease of buried depth of pipelines, the bottom tension strain increases gradually. Taking the shallow-buried pipelines as an example, the tensile strain of the bottom of the asphalt layer increases by $79.24 \%$ compared with that of the nonpipeline condition.

The buried depth of pipeline has great influence on the stress state of pavement structure. The pavement structure as a whole is mainly under compression, but there is tension at the bottom of the asphalt underlayer. The vertical strain 


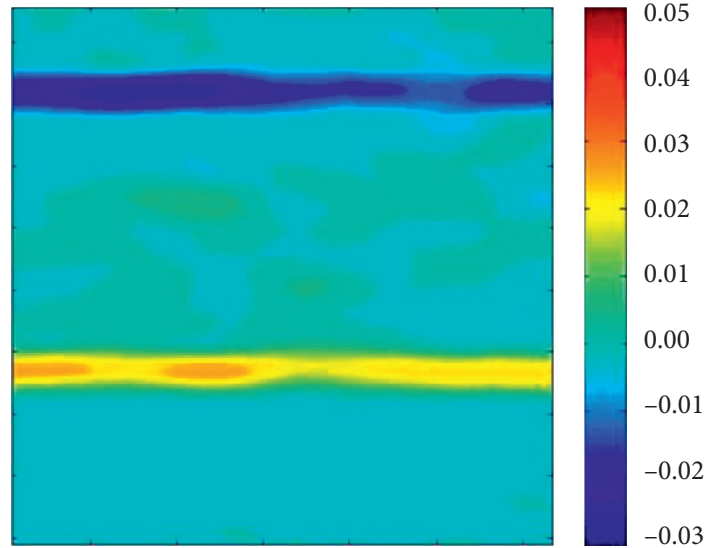

Figure 11: Vertical strain of no buried pipe.
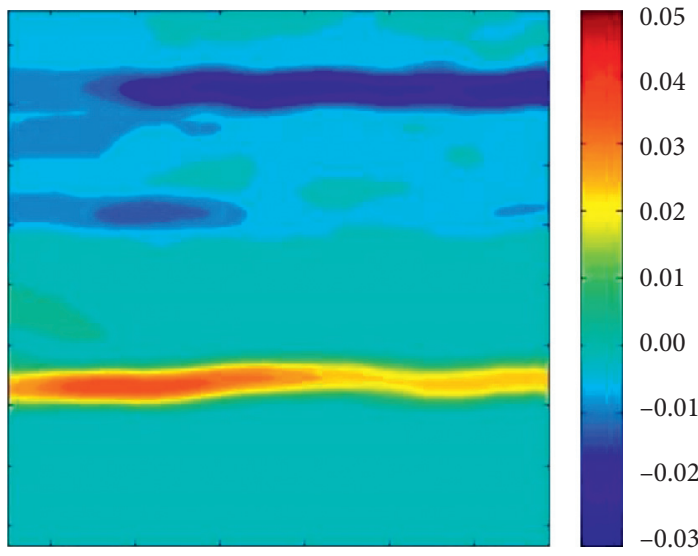

FIgURE 12: Vertical strain of deep-buried pipe.

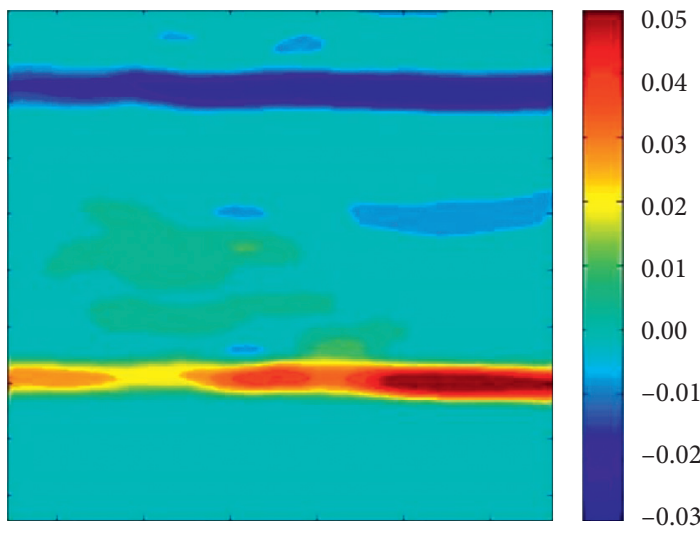

FIGURE 13: Vertical strain of middle-buried pipe.

value of pavement structure is discontinuous and abrupt. Strain concentration appears at the bottom of each layer. The maximum strain of each layer appears at the bottom of the layer.

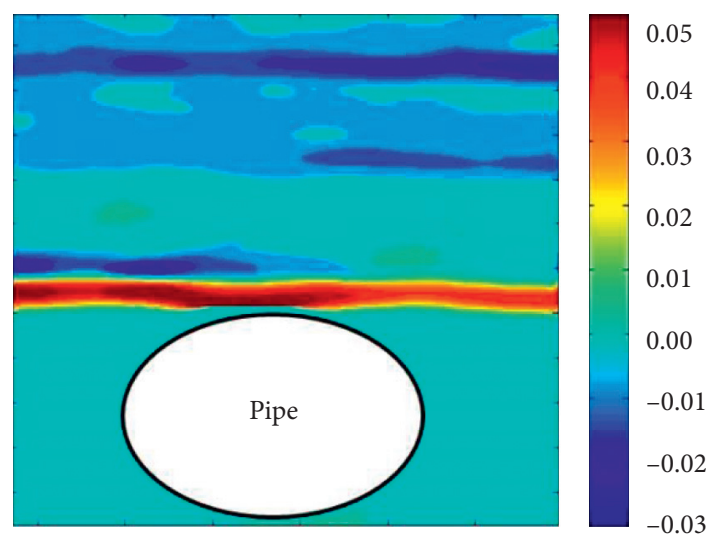

FIGURE 14: Vertical strain of shallow-buried pipe.

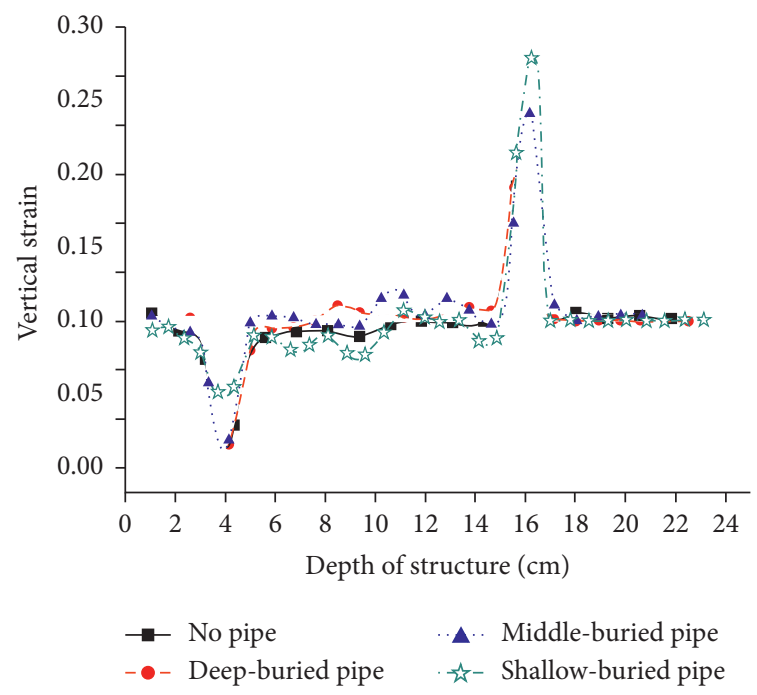

FIgURE 15: Vertical strain curve of buried pipe structure.

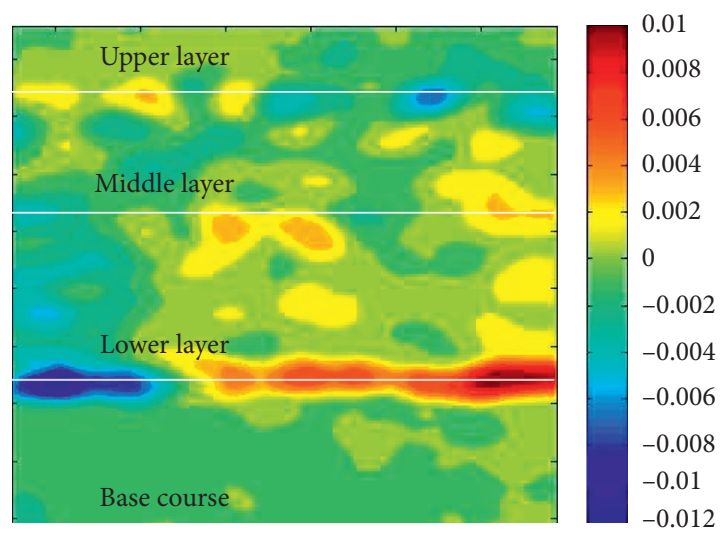

FIgURE 16: Shear strain of no buried pipe.

4.3. Analysis of the Influence of Buried Pipeline on Shear Strain of Pavement Structure. Shear stress can cause surface cracking, rutting, sliding, and other damages. Figures 16-19 


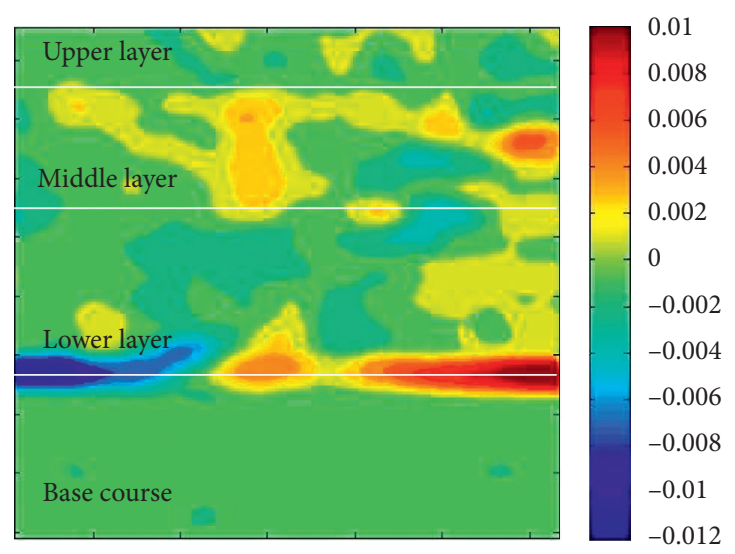

Figure 17: Shear strain of deep-buried pipe.

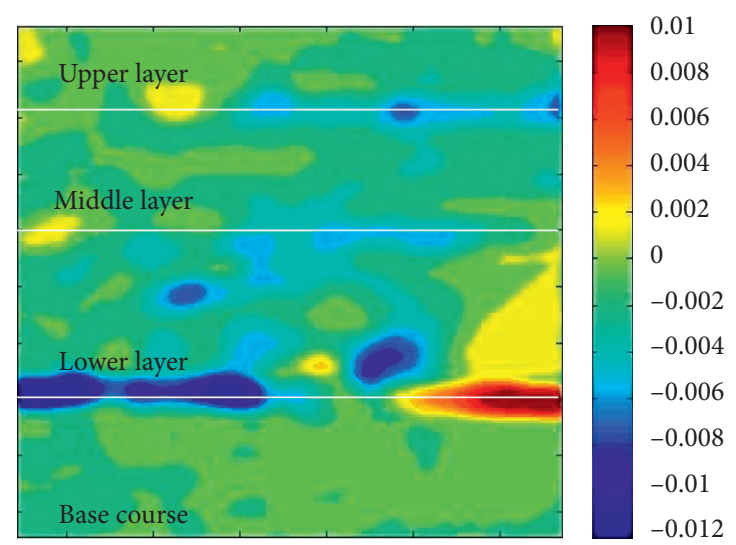

FIGURE 18: Shear strain of middle-buried pipe.

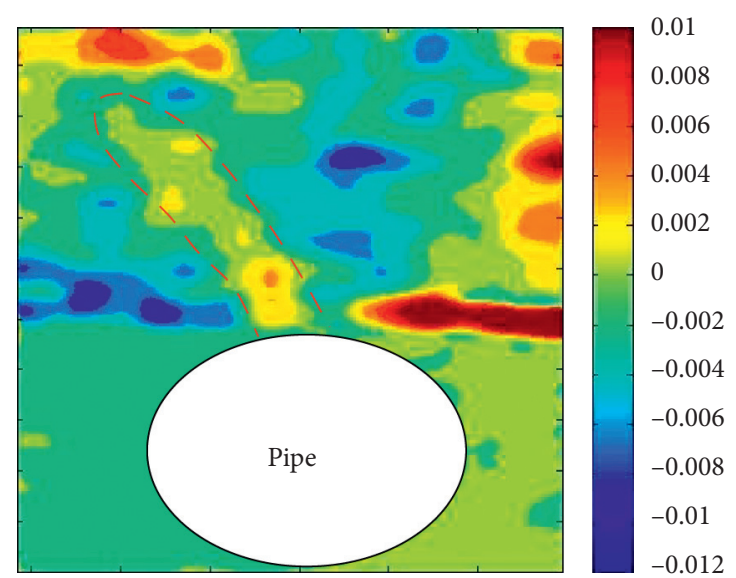

Figure 19: Shear strain of shallow-buried pipe.

show the distribution of shear strain in the pavement structure analysis area under different buried depths.

The maximum shear strain at the bottom of each layer of pavement structure is obtained by sorting out the shear strain data observed in Figures 16-19, as shown in Table 4.

From Figures 16-19 and Table 4, it can be seen that (1) in the pavement structure, the phenomenon of shear strain concentration also occurs at the bottom of each layer, that is, the maximum shear strain of each layer occurs at the bottom of this layer. (2) As shown in Table 4, the maximum shear strain of pavement structure appears at the bottom of the asphalt layer, the second is at the top layer, and the smallest is at the middle layer. The shear strain of the asphalt underlayer is 1.74-4.53 times of that of the other two layers. (3) With the 
TABLE 4: Maximum shear strain of the asphalt layer bottom.

\begin{tabular}{|c|c|c|c|}
\hline Condition & Bottom of the upper layer/ $\mathcal{\varepsilon}$ & Bottom of the middle layer/ $\varepsilon$ & Bottom of the lower layer $/ \varepsilon$ \\
\hline No pipeline & 0.00636 & 0.00398 & 0.01108 \\
\hline Deep-buried pipe & 0.00629 & 0.00379 & 0.01367 \\
\hline Rangeability & $-1.24 \%$ & $-4.72 \%$ & $23.38 \%$ \\
\hline Middle-buried pipe & 0.00625 & 0.00466 & 0.01380 \\
\hline Rangeability & $-1.82 \%$ & $17.07 \%$ & $24.62 \%$ \\
\hline Shallow-buried pipe & 0.00516 & 0.00572 & 0.02337 \\
\hline Rangeability & $-18.91 \%$ & $43.86 \%$ & $110.97 \%$ \\
\hline
\end{tabular}

decrease of buried depth of the pipelines, the shear strain of the asphalt layer increases obviously. Taking the case of the shallowly buried pipelines as an example, the shear strain at the bottom of the asphalt subsurface increases by $110.97 \%$ compared with that without a pipeline. (4) Under the condition of the shallowly buried pipelines, the shear strain concentration trend of asphalt pavement under standard driving load has appeared, which is inclined to the upper left, as shown in Figure 19. Therefore, the burial of pipelines will accelerate the occurrence of shear failure of the pavement structure.

To sum up, the embedding of pipelines will accelerate the occurrence of shear failure of pavement structure. Similar to the vertical strain, the shear strain is also discontinuous and abrupt. The bottom shear strain of each layer is concentrated. With the decrease of the buried depth of the pipeline, the shear strain of the asphalt layer increases obviously.

\section{Conclusion}

The digital speckle correlation method (DSCM) has been used to study the load-bearing characteristics of asphalt pavement with buried pipeline under driving load. The experiment has been conducted in the study of the mechanical properties of the asphalt pavement structure of the unpaved and three different kinds of buried tunnels, studied under four different conditions of the asphalt structure and the vertical displacement and the strain value of each layer of asphalt pavement. The influence of the pipeline to the structural bearing properties of asphalt pavement is obtained by contrast analysis.

(1) The digital speckle observation test method can accurately obtain the displacement and strain values of each layer of asphalt pavement structure containing buried pipeline, and the application effect is good. Compared with the traditional contact strain measurement method, this method is simple and accurate and can provide effective analysis data for experimental research.

(2) Because the road structure material is layered, the strength of the material is different for each layer. There is an interlayer effect in the process of stress on asphalt pavement structure, which is mainly reflected in the discontinuity of vertical displacement and strain between layers, and there is a mutation. At the same time, vertical strain and shear strain concentrate at the bottom of each layer. The interlayer effect between the upper layer and the lower layer of asphalt is the most prominent.

(3) The supporting action of the pipeline reduces the vertical displacement of each layer and increases the tension and compression and shear strain of each layer. Pipeline embedding has the greatest influence on the asphalt underlayer, which accelerates the destruction of asphalt pavement structure.

\section{Data Availability}

The data used to support the findings of this study have not been made available because the data also form part of an ongoing study.

\section{Conflicts of Interest}

The authors declare that they have no conflicts of interest.

\section{References}

[1] D. Chen, Digital Speckle Correlation Technique and its Application in Monitoring Structure, Suzhou University, Jiangsu, China, 2005.

[2] J. Du, Theoretical Lnvestigation Numerical Simulation and Experimental Research of Manhole Settlement under Traffic Load, Zhejiang University, Hangzhou, China, 2006.

[3] L. Liu, Study on the Technology Performance of Asphalt Pavement Layer Interfaces, Chang'an University, Xi'an, China, 2008.

[4] X. L. Li, S. Z. Li, and Y. G. Shen, "Stress analysis and field testing of buried pipeline under traffic load," Journal of Zhejiang University, vol. 48, no. 11, pp. 1976-1982, 2014.

[5] W. H. Peters and W. F. Ranson, "Digital imaging techniques in experimental tress analysis," Optical Engineering, vol. 21, no. 3, pp. 427-431, 1982.

[6] Z. M. Wang, Study on Mechanical Behaviors of Buried Pipelines under Traffic Loads, Zhejiang University, Hangzhou, China, 2006.

[7] Y. H. Wang, H. Liang, S. Wang, H. Zhang, and L. X. Yang, "Advance in digital speckle correlation method and its applications," Chinese Optics, vol. 6, no. 4, pp. 470-480, 2013.

[8] X. D. Wang, "Design of pavement structure and material for full - scale test track," Journal of Highway and Transportation Research and Development, vol. 34, no. 6, pp. 30-37, 2017.

[9] B. Pan, H. Xie, and F. L. Dai, "AN investigation of SUB-pixel displacements registration algorithms IN digital image correlation," Chinese Journal of Theoretical and Applied Mechanics, vol. 7, no. 2, pp. 245-252, 2007. 
[10] I. Yamaguchi, “A laser-speckle strain gauge," Journal of Physics E: Scientific Instruments, vol. 14, no. 11, pp. 1270-1273, 1981.

[11] J. T. Yang, Research on Longitudinal Mechanical Characteristics of Pipelines Buried in Soft Soil under Vertical Loads, Zhejiang University, Hangzhou, China, 2006.

[12] J. Zhao, Research on Digital Speckle Correlation Method and its Applications in Mechanical Engineering Measurement, Beijing Forestry University, Beijing, China, 2014. 